\title{
Yang-Dan-Tang, Identified from 15 Chinese Herbal Formulae, Inhibits Human Lung Cancer Cell Proliferation via Cell Cycle Arrest
}

\author{
Tien-Chun Wang, ${ }^{1}$ Chih-Nan Fang, ${ }^{2}$ Chih-Chien Shen, ${ }^{1}$ Hui-Yu Wei, ${ }^{1}$ Yui-Ping Weng, ${ }^{3}$ \\ Jung-Yaw Lin, ${ }^{4}$ Hsiu Mei Hsieh-Li, ${ }^{1}$ and Chen-Yu Lee ${ }^{5}$
}

${ }^{1}$ Department of Life Science, National Taiwan Normal University, Taipei 116, Taiwan

${ }^{2}$ Kuo-Hsing Chinese Clinic, Taipei 110, Taiwan

${ }^{3}$ Department of Biological Science and Technology, Chung Hwa University of Medical Technology, Tainan 717, Taiwan

${ }^{4}$ Institute of Biochemistry and Molecular Biology, College of Medicine, National Taiwan University, Taipei 100, Taiwan

${ }^{5}$ Yu-Sheng Chinese Clinic, Taipei 106, Taiwan

Correspondence should be addressed to Hsiu Mei Hsieh-Li, hmhsieh@ntnu.edu.tw and Chen-Yu Lee, chenyr.lee@msa.hinet.net

Received 16 November 2011; Revised 29 February 2012; Accepted 26 March 2012

Academic Editor: Richard Pietras

Copyright ( $) 2012$ Tien-Chun Wang et al. This is an open access article distributed under the Creative Commons Attribution License, which permits unrestricted use, distribution, and reproduction in any medium, provided the original work is properly cited.

Lung cancer has long been one of the most deadly forms of cancer. The majority of lung cancers are of the non-small-cell lung cancer (NSCLC) type. Here we used the non-small-cell lung carcinoma cell line A549 to screen 15 different traditional Chinese herbal medicine (CHM) formulae to explore the possible mechanisms of alternative medicine in lung cancer therapy. We identified three formulae (Formulae 3, 5, and 14) that substantially decreased the survival of A549 cells but did not affect MRC5 normal lung tissue cells. Formula 14, Yang-Dan-Tang, a modified decoction of Ramulus Cinnamomi Cassiae, was chosen for further characterization. Flow cytometry analysis showed that treatment of Formula 14 induced cell cycle arrest in G1 and G2 phase without causing significant cell death. These results were also confirmed by Western blot analysis, with decreased expression of G1/S and G2/M promoting cell cycle machinery including cyclin D3, cyclin B1, CDK4, and CDK6. This study provides further insight into the possible working mechanism of Yang-Dan-Tang in patients.

\section{Introduction}

Lung cancer, with high incidence and mortality, has long been the most deadly cancer disease. Most lung cancers are carcinomas, and non-small-cell lung carcinoma accounts for more than $80 \%$ of these [1]. Although there are many therapeutic approaches toward cancer, none of the treatments can yet substantially cure cancer patients. The development of new drugs and therapies is therefore still of great urgency.

Chinese herbal medicine (CHM) has been used to treat lung cancers for centuries in East Asia. CHM is the most important therapeutic modality of traditional Chinese medicine (TCM). There are more than $130 \mathrm{CHMs}$ that have been reported to have anti-lung-cancer ability [2] and about
40 CHMs [3] and 30 formulae have been frequently used for lung cancer patients [4]. CHMs are usually applied to patients in a form of formula, and each formula may contain more than three herbs. Generally there are one or two major ingredients toward the disease therapy and other ingredients were used to adjust the yin yang extent of the formula according to the patient's status $[5,6]$. Some of CHMs are also used in patients under chemotherapies or radiotherapies to reinforce patients' immune activity and metabolism for improving overall prognosis $[7,8]$. Although the use of CHMs as therapeutic approaches is very common in East Asia, the specific mechanisms of how CHMs affect the disease still remain largely unknown.

Many studies have used A549 NSCLC lung cancer cells to evaluate the effects of herbs and herb constituents on 
lung cancers. Plumbagin, phenylbutenoid, and parthenolide were demonstrated to inhibit proliferation of A549 cells [9-11], cantharidin, curcumin, and gambogic acid were reported to induce apoptosis of A549 cells [12-14], and ginsenoside was suggested to have antimetastatic potential toward A549 cells [15]. However, most studies focused on the effects of one single herb toward cancer cells, but not the prescribed multiple herb formula which patients normally take. In this study, we used A549 cells as an NSCLC model to test 15 different $\mathrm{CHM}$ formulae which are considered by TCM physicians to have some potential in treating cancers (Table 1).

\section{Materials and Methods}

2.1. Cell Culture and Herbal Formula Preparation. The NSCLC cell lines A549 (carcinoma), NCI-H460 (H460, large cell carcinoma), and NCI-H520 (H520, squamous cell carcinoma) and the normal cell line MRC5 were purchased from Bioresource Collection and Research Center (BCRC, Taiwan) and cultured with F12K (for A549), RPMI1640 (for both $\mathrm{H} 460$ and H520), and MEM (for MRC5) medium containing $10 \%$ FBS, respectively, in a $37^{\circ} \mathrm{C}, 5 \% \mathrm{CO}_{2}$ incubator. MRC5 cells are normal fetal lung fibroblast cells and used as noncancerous cells in many in vitro lung cancer cytotoxicity studies [16-18]. The 15 different CHM formulae (Table 1) were used to prepare the herbal decoctions as normally prescribed by a CHM doctor for patients. The herbs were boiled in $1.2 \mathrm{~L}$ of water for $1 \mathrm{hr}$ to generate the final decoction (around $450 \mathrm{~mL}$ ), and aliquots were stored at $4^{\circ} \mathrm{C}$. To prevent instability and unequal recovery of different ingredients of each formula, concentration under vacuum evaporator was not conducted for all these 15 decoctions. Each formula was applied to cell cultures after decoction debris was removed by passing the liquid through a $0.22 \mu \mathrm{m}$ membrane filter.

2.2. Cell Proliferation Assay. Three different concentrations of the 15 formula decoctions, $1 \%, 2 \%$, and $10 \%(\mathrm{v} / \mathrm{v})$, were applied to A549 cells to determine the $\mathrm{IC}_{50}$ of each formula. The maximum 10\% decoction was used to avoid dilution of the medium by a large volume of decoction. A549 cells were seeded at $1 \times 10^{4}$ cells per well in a 24-well plate to ensure cells grow logarithmically during total treatment period. Different decoctions were added to the cells $24 \mathrm{hr}$ after seeding, and cell growth was determined by MTT assays after cells were treated for $72 \mathrm{hr}$.

To test the nontarget effects, $\mathrm{IC}_{50}$ of the eight formulae toward A549 (F3: 4\%, F4: 8.4\%, F5: 2.2\%, F6: 9\%, F8: 0.4\%, F9: 4.2\%, F14: 7\%, F15: 4\%) were applied to A549 and MRC5 cells at the same time. Cell growth was examined by MTT assay after a $72 \mathrm{hr}$ treatment. For time course studies, 7\% (v/v) of Formula 14 was applied to A549 cells and MTT assay was performed with these cells after treatment for $0,24,48$, and $72 \mathrm{hr}$, respectively. For H460 and H520 cell lines, different amounts of Formula 14 (2-10\%) were applied for MTT assay.
2.3. Apoptosis Analysis. Characterization of the apoptosis status of A549 cells after Formula 14 (7\%) treatment was performed with annexin-V-FLUOS Staining Kit (Roche, Mannheim, Germany) according to the protocol provided by manufacturer. Briefly, $1 \times 10^{5}$ A549 cells were seeded on one $6 \mathrm{~cm}$ plate. After treatment for $72 \mathrm{hr}$, cells were harvested and resuspended with prediluted staining buffer (Annexin-V-Fluos labeling reagent, propidium iodide, and incubation buffer $1: 1: 50$, resp., $100 \mu \mathrm{L}$ for $1 \times 10^{6}$ cells). After incubation for $15 \mathrm{~min}$ in the dark and sieving through $35 \mu \mathrm{m}$ nylon mesh, cells were analyzed using FACSCalibur (BD Biosciences, San Jose, CA, USA).

2.4. Colony-Forming Assay. The colony-forming assay was modified from previous studies $[19,20]$. In brief, A549 and H460 cells treated with Formula 14 (7\% and 4.3\%, resp.) or vehicle for $72 \mathrm{hr}$ were harvested and seeded onto a $6-\mathrm{cm}$ dish (500 cells) and cultured in a $37^{\circ} \mathrm{C}, 5 \% \mathrm{CO}_{2}$ incubator for 14 days. The dishes were then removed from the incubator and the medium was discarded. After washing with PBS, the cells were fixed with cold methanol for $10 \mathrm{~min}$. The fixed cells were then stained with crystal violet (Sigma, St. Louis, MO, USA) for $3 \mathrm{~min}$ at room temperature. The number of cell colonies in the central $12.25 \mathrm{~cm}^{2}$ of the dishes was counted to represent the colony-forming ability of the cells.

2.5. Soft Agar Assay. Bacto agar (1.8\%) and $2 \times \mathrm{F} 12 \mathrm{~K} /$ DMEM were mixed $(1: 1)$ and used to coat the base of a 6-well plate to form a $0.9 \%$ agar base. A549 cells treated with Formula $14(7 \%)$ or vehicle for $72 \mathrm{hr}$ were harvested and 1000 cells were mixed with $1.3 \%$ methylcellulose and $2 \times$ F12K/DMEM $(1: 1)$ and seeded onto the $0.9 \%$ agar plate. The cells were then incubated at $37^{\circ} \mathrm{C}, 5 \% \mathrm{CO}_{2}$ in an incubator for one month. Cell colonies in the central $6.5 \mathrm{~cm}^{2}$ of the plates were directly counted under microscope to represent the colony-forming ability of cells on soft agar.

2.6. Cell Cycle Analysis. A549 cells were seeded at a density of $1 \times 10^{5}$ cells on $6 \mathrm{~cm}$ plates, and Formula $14(7 \%)$ was applied to the cells after culture for $24 \mathrm{hr}$. Cells were incubated for different time periods then fixed with $70 \%$ $\mathrm{EtOH}$ and stained with propidium iodide for $30 \mathrm{~min}$ at $37^{\circ} \mathrm{C}$ in the dark with frequent shaking. Cells were sieved through a $35 \mu \mathrm{m}$ nylon mesh and immediately analyzed using FACSCalibur. The percentages of cells at different cell cycle phases were calculated with ModFit software (Verity, Software House, Topsham, ME, USA).

2.7. Ki67 Analysis. After treatment with Formula 14 (7\%) for $72 \mathrm{hr}$, cells were fixed and stained with Ki67 antibody and PI using the PE Mouse Anti-Human Ki-67 Set (BD Pharmingen) according to the manufacturer's instruction, with slight modification. Nonspecific PE-conjugated isotype antibody was used as control in this analysis. Both nonstained and single-stained groups were included in the fluorescence compensation. All samples were filtered through $35 \mu \mathrm{m}$ nylon mesh before entering the flow cytometer (LSR II, BD 
TABLE 1: The composition of 15 herbal formulae.

Formula 1

Angelicae Sinensis 11.25 g, Ligustici Chuanxiong 11.25 g, Paeoniae Rubrae 11.25 g, Rehmanniae Glutinosae 11.25 g, Gummi Olibanum 11.25 g, Myrrha 11.25 g, Atractylodis Rhizoma 11.25 g, Raw Radix Glycyrrhizae Uralensis 11.25 g, Semen Persicae 11.25 g, Flos Carthami Tinctorii $1.875 \mathrm{~g}$

Formula 2 Angelicae Sinensis 11.25 g, Ligustici Chuanxiong 11.25 g, Paeoniae Rubrae 11.25 g, Rehmanniae Glutinosae $11.25 \mathrm{~g}$

ormula 3

Rhizoma Coptidis 11.25 g, Radix Scutellariae Baicalensis $11.25 \mathrm{~g}$, Cortex Phellodendri $11.25 \mathrm{~g}$, Fructus Gardeniae Jasminoidis 11.25 g, Raw Radix Glycyrrhizae Uralensis 18.75 g, Atractylodis Rhizoma $15 \mathrm{~g}$

Radix Gentianae Longdancao 11.25 g, Radix Scutellariae Baicalensis 11.25 g, Fructus Gardeniae

Formula 4 Jasminoidis $7.5 \mathrm{~g}$, Angelicae Sinensis $11.25 \mathrm{~g}$, Rehmanniae Glutinosae $11.25 \mathrm{~g}$, Caulis Mutong 11.25 g, Radix Bupleuri 11.25 g, Semen Plantaginis 11.25 g, Atractylodis Rhizoma 15 g, Rhizoma Alismatis Orientalis $15 \mathrm{~g}$, Raw Radix Glycyrrhizae Uralensis $18.75 \mathrm{~g}$

Formula 5

Rhizoma Coptidis 11.25 g, Rhizoma Cimicifugae 11.25 g, Angelicae Sinensis 11.25 g, Rehmanniae Glutinosae $11.25 \mathrm{~g}$, Cortex Moutan Radicis $11.25 \mathrm{~g}$

Fructus Forsythiae Suspensae 11.25 g, Herba Menthae Haplocalycis 11.25 g, Fructus Gardeniae

Formula 6 Jasminoidis $11.25 \mathrm{~g}$, Radix Scutellariae Baicalensis $11.25 \mathrm{~g}$, Herba Lophatheri Gracilis $11.25 \mathrm{~g}$, Raw Radix Glycyrrhizae Uralensis 11.25 g, Radix et Rhizoma Rhei 3.75 g, Mirabilitum 3.75 g, Atractylodis Rhizoma $15 \mathrm{~g}$

Formula 7 Pericarpium Citri Reticulatae 15 g, Rhizoma Pinelliae Ternatae 15 g, Sclerotium Poriae Cocos 15 g, Raw Radix Glycyrrhizae Uralensis 15 g, Radix Scutellariae Baicalensis 11.25 g, Fructus Immaturus Citri Aurantii $11.25 \mathrm{~g}$, Caulis Bambusae in Taeniis 3ea, Fructus Zizyphi Jujubae 5ea

Angelicae Sinensis 11.25 g, Ligustici Chuanxiong 11.25 g, Paeoniae Rubrae 11.25 g, Rehmanniae

Formula 8 Glutinosae 11.25 g, Radix Glycyrrhizae Uralensis 11.25 g, Radix Scutellariae Baicalensis $11.25 \mathrm{~g}$, Cortex Lycii Radicis 18.75 g, Cortex Moutan Radicis 18.75 g, Atractylodis Rhizoma $15 \mathrm{~g}$

Angelicae Sinensis 11.25 g, Ligustici Chuanxiong 11.25 g, Radix Paeoniae Lactiflorae $11.25 \mathrm{~g}$, Rehmanniae Glutinosae 11.25 g, Fried Atractylodis Macrocephalae 11.25 g, Radix Glycyrrhizae

Formula 9 Uralensis 11.25 g, Radix Dipsaci Asperi 11.25 g, Cortex Eucommiae Ulmoidis 11.25 g, Radix Scutellariae Baicalensis 11.25 g, Radix Dioscoreae Oppositae 18.75 g, Folium Artemisiae Argyi $18.75 \mathrm{~g}$

Formula 10

Radix Achyranthis Bidentatae 30 g, Radix Dipsaci Asperi 30 g, Rhizoma Drynariae 30 g, Rubiaakane Nakai $30 \mathrm{~g}$, Raw Radix Glycyrrhizae Uralensis $18.75 \mathrm{~g}$, Atractylodis Rhizoma $15 \mathrm{~g}$

Formula 11

Angelicae Sinensis 30 g, Radix Polygoni Multiflori 30 g, Semen Cuscutae Chinensis 30 g, Semen Astragali Complanati $30 \mathrm{~g}$, Tribulus terrestris Linn $15 \mathrm{~g}$, Atractylodis Rhizoma $15 \mathrm{~g}$

Angelicae Sinensis 11.25 g, Ligustici Chuanxiong 11.25 g, Paeoniae Rubrae 7.5 g, Rehmanniae

Formula 12 Glutinosae 11.25 g, Radix Salviae Miltiorrhizae 18.75 g, Atractylodis Rhizoma 18.75 g, Radix Astragali Membranacei $56.25 \mathrm{~g}$

Formula 13

Radix Astragali Membranacei 75 g, Angelicae Sinensis 15 g, Ligustici Chuanxiong 15 g, Paeoniae Rubrae 15 g, Ginkgo Bilobae $15 \mathrm{~g}$

Ramulus Cinnamomi Cassiae 18.75 g, Paeoniae Rubrae 18.75 g, Raw Radix Glycyrrhizae

Formula 14 Uralensis 18.75 g, Rhizoma Zingiberis Officinalis Recens 18.75 g, Radix Scutellariae Baicalensis 11.25 g, Fructus Zizyphi Jujubae 5ea

Formula 15

Rhizoma Cimicifugae 7.5 g, Rehmanniae Glutinosae 56.25 g, Paeoniae Rubrae 37.5 g, Cortex Moutan Radicis $37.5 \mathrm{~g}$, Radix Scutellariae Baicalensis $37.5 \mathrm{~g}$

Biosciences). The data were analyzed with FlowJo software (TreeStar, Ashland, OR, USA).

2.8. Western Blot Analysis. Molecules involved in cell cycle regulation were examined using Western blot analyses. A549, $\mathrm{H} 460$, and $\mathrm{H} 520$ cells were seeded at $2 \times 10^{5}, 7 \times 10^{4}$, and $5 \times 10^{5}$ cells, respectively, on $10 \mathrm{~cm}$ plates and harvested after treatment for $72 \mathrm{hr}$. Cells were lysed with RIPA buffer (100 mM Tris pH 7.5, $50 \mathrm{mM} \mathrm{NaCl}, 5 \mathrm{mM}$ EDTA pH 8.0, 1\% SDS, $1 \%$ sodium deoxycholate, $1 \% \mathrm{NP} 40)$. Ten $\mu \mathrm{g}$ protein of each sample was electrophoresed by SDS-PAGE and then transferred onto Hybond-C extra membrane (Amersham, GE Healthcare, UK). The membrane was blocked with 5\% nonfat dry milk powder in Tris-buffered saline with $0.1 \%$ Tween-20 for $1 \mathrm{hr}$ at room temperature. After blocking, the membrane was incubated with the primary antibody [Cyclin D3, 1:1000; CDK4, 1:1000; CDK6, 1:1000; cdc2, $1: 1000$; pcdc2, $1: 1000$ and pRb,1:1000 (Cell Signaling, Danvers, MA, USA); cyclin B1, $1: 1000$ (Upstate, Lake Placid, NY, USA)]. The corresponding HRP-conjugated secondary 
TABLE 2: Cytotoxicity of 15 CHM formulae against A549 cells.

\begin{tabular}{lcccc}
\hline Formula $(\mathrm{v} / \mathrm{v})$ & $1 \%$ & $2 \%$ & $10 \%$ & $\mathrm{IC}_{50}$ conc. \\
\hline Formula 1 & $111 \%$ & $98 \%$ & $77 \%$ & $\mathrm{NA}$ \\
Formula 2 & $106 \%$ & $109 \%$ & $95 \%$ & $\mathrm{NA}$ \\
Formula 3* & $67 \%$ & $60 \%$ & $32 \%$ & $4 \%$ \\
Formula 4* & $96 \%$ & $96 \%$ & $35 \%$ & $8.4 \%$ \\
Formula 5* & $57 \%$ & $46 \%$ & $28 \%$ & $2.2 \%$ \\
Formula 6* & $89 \%$ & $83 \%$ & $29 \%$ & $9 \%$ \\
Formula 7 & $105 \%$ & $106 \%$ & $61 \%$ & $\mathrm{NA}$ \\
Formula 8* & $24 \%$ & $11 \%$ & $5 \%$ & $0.4 \%$ \\
Formula 9* & $107 \%$ & $80 \%$ & $7 \%$ & $4.2 \%$ \\
Formula 10 & $104 \%$ & $86 \%$ & $51 \%$ & $\mathrm{NA}$ \\
Formula 11 & $83 \%$ & $87 \%$ & $65 \%$ & $\mathrm{NA}$ \\
Formula 12 & $94 \%$ & $95 \%$ & $69 \%$ & $\mathrm{NA}$ \\
Formula 13 & $104 \%$ & $102 \%$ & $62 \%$ & $\mathrm{NA}$ \\
Formula 14* & $97 \%$ & $77 \%$ & $41 \%$ & $7 \%$ \\
Formula 15* & $76 \%$ & $70 \%$ & $12 \%$ & $4 \%$ \\
\hline
\end{tabular}

${ }^{*}$ Indicates the proliferation inhibition exceeds $50 \%$ under the maximum dose.

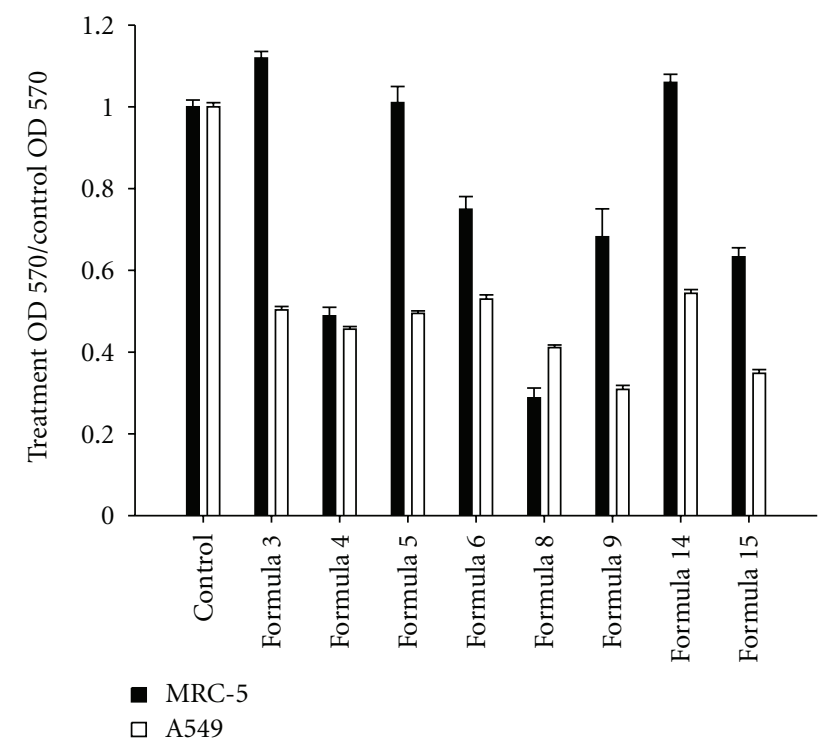

Figure 1: Effect of $8 \mathrm{CHM}$ formulae on the cytotoxicity of A549 cells. Survival rate of A549 and MRC5 cells following treatment at the $\mathrm{IC}_{50}$ with the 8 chosen formulae for $72 \mathrm{hr}$ was analyzed by MTT assay. Data were normalized to control groups. Formulae 3, 5, and 14 decreased the survival rate of A549 cells around 50\% without affecting that of MRC5 cells.

antibody was applied to the membrane for $1 \mathrm{hr}$ to highlight the specific signal. HRP substrate (Millipore, MA. USA) was added onto blot membrane to show the hybridization pattern, and images were acquired with imaging system LAS3000 (Fujifilm, Japan). Blot images were quantified with Multi-Gauge software (Fujifilm).

2.9. Statistical Analysis. Data are presented as mean \pm SE. Student's $t$-test was performed with SPSS software to evaluate the significance of differences between group means. A $P$-value of less than 0.05 was considered to be significant.

\section{Results}

3.1. Cytotoxicity Analysis of 15 TCM Formulae. MTT assays were performed with the NSCLC cell line A549 after treatment with different formulae for $72 \mathrm{hr}$. Of the 15 formulae, Formulae 3, 4, 5, 6, 8, 9, 14, and 15, substantially reduced the growth rate of A549 cells over 50\% at the highest 10\% (v/v) dosage (Table 2). The $\mathrm{IC}_{50}$ of the 8 formulae were calculated using the interpolation method and are listed in Table 2. Among these 8 formulae, Radix Scutellariae Baicalensis is one of the dominant ingredients in 7 of them, except for Formula 5. Radix Scutellariae Baicalensis is also an ingredient of Formula 7 although $10 \%(\mathrm{v} / \mathrm{v})$ reduced cell viability to $61 \%$. Whether Radix Scutellariae Baicalensis is the major component that decreases the growth of cells needs further investigation.

To test whether these 8 active formulae have any significant nontarget effect, the normal lung cell line MRC5 was included in the cytotoxicity screening. The eight formulae were used to treat A549 and MRC5 cell lines for $72 \mathrm{hr}$ at their $\mathrm{IC}_{50}$ toward A549. We found that Formulae 3, 5, and 14 reduced the growth rate of A549 cells around 50\% without significantly affecting the viability of MRC5 cells (Figure 1 ). In contrast, the other 5 formulae $(4,6,8,9$, and 15$)$ showed significant nontarget effects, suppressing the growth rate of MRC5 about 20-70\% (Figure 1). Among the three A549specific formulae, Formula 14, Yang-Dan-Tang, a modified decoction of Ramulus Cinnamomi Cassiae, was chosen for further study due to its traditional CHM use as therapy for lung disease.

3.2. CHM Formula 14 Reduced A549 Cells Proliferation without Inducing Massive Apoptosis. To further elucidate the growth inhibiting mechanisms of Formula 14, the time course of the response of A549 cells to Formula 14 treatment was examined. Formula 14 could significantly decreased the A549 cell numbers after $24 \mathrm{hr}$ treatment (Figure 2(a)), suggesting that Formula 14 could either actually kill the cells or inhibit the proliferation of the cells. The cell density of the Formula 14 treated group was much lower than that of control group; however, few dead cells could be seen under microscope observation (Figure 2(b)).

To further clarify the two possibilities, Annexin V and propidium iodide double staining was performed to see if cell death occurred after treatment. No significant difference was identified for the healthy populations between Formula 14-treated and control groups (Figures 2(c) and 2(d)). In addition, little cell death (early apoptosis, late apoptosis, or necrosis) was identified in both the Formula 14-treated and control groups (Figure 2(c)). These results suggest that Formula 14 treatment reduction of the cell number might be through inhibition of proliferation. 


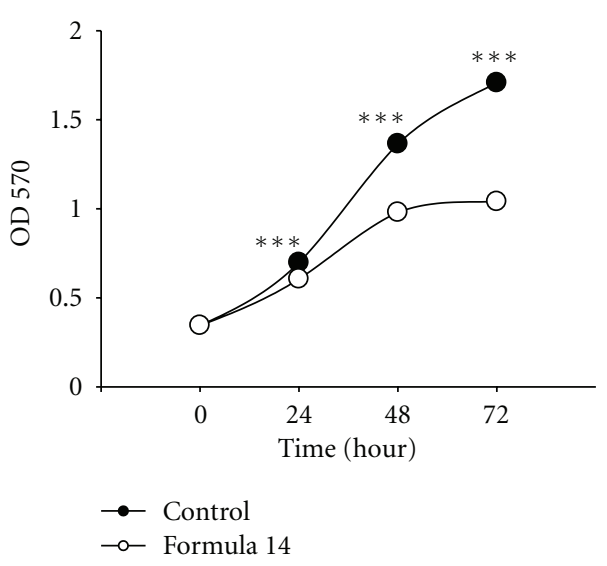

(a)

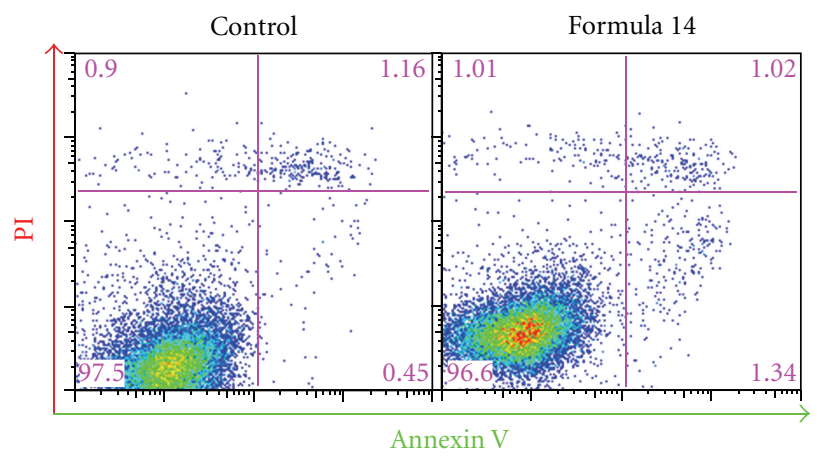

(c)
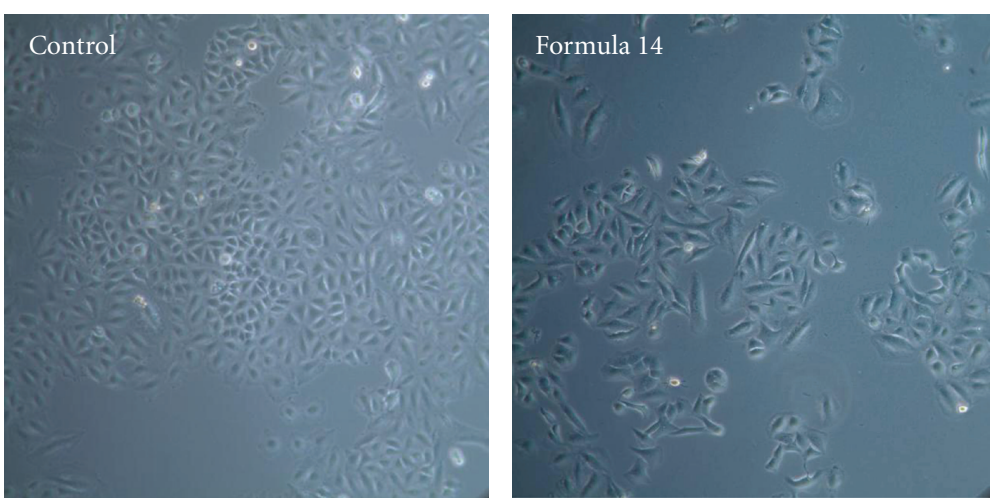

(b)

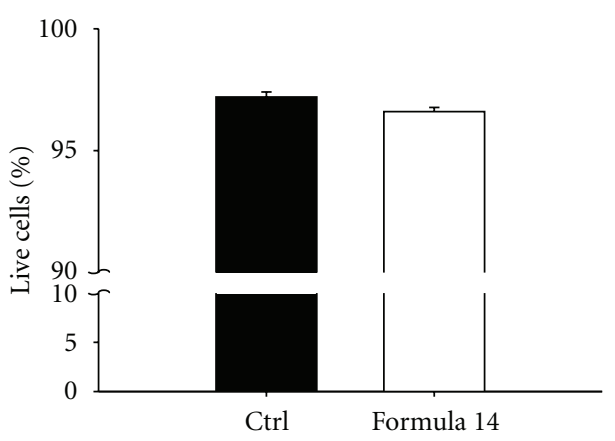

(d)

FIgURE 2: CHM Formula 14 decreased A549 cell survival without apparent apoptosis. A time course MTT assay was used to investigate the response of A549 cells to treatment with Formula 14. (a) Formula 14 treatment significantly inhibited the proliferation of A549 cells at all the time points studied. (b) Bright field images of A549 cells after $72 \mathrm{hr}$ treatment with vehicle or Formula 14 . The cell density of A549 cells after treatment with Formula 14 was much lower than the control group. (c) Representative data of annexin V and PI double staining show the apoptosis/necrosis status of A549 cells after $72 \mathrm{hr}$ treatment with Formula 14. (d) Percentages of the double negative live cells (bottom left square) were quantified to compare the healthy population. Formula 14 has no effect on the live cell percentage. Student's $t$-test:, ${ }^{* * *} P<0.001$.

to determine whether Formula 14 could affect the tumorigenesis ability of A549 cells, and the results showed that the number of colonies at 14-day culture was significantly reduced in cells pretreated with Formula 14 compared to that of the control group (Figures 3(a) and 3(b)). In addition, the formation of colonies on soft agar after one month was also dramatically decreased in the Formula 14-treated cells (Figure 3(c)). These two different assays revealed that Formula 14 could reduce tumorigenesis in A549 cells.

3.4. CHM Formula 14 Induced A549 Cell Cycle Arrest at G1 and G2 Phases. We then tested whether Formula 14 affected cell cycle progression, and the results showed that the number of cells in the proliferative $S$ phase was significantly decreased whereas cell populations in G1 and G2 phases were significantly increased after 24 and $72 \mathrm{hr}$ treatment, respectively (Figures 4(a) and 4(b)). However, there was no cell population identified in the subG1 phase (Figure 4(a)). These data indicate that CHM Formula 14 treatment did not induce cell apoptosis but rather reduced the proliferation rate of A549 cells. In addition, a Ki67 analysis showed there were more cells in the quiescent G0 phase after treatment with Formula 14, compared to that of the control group (Figures 4(c) and 4(d)). In conclusion, CHM Formula 14 retarded cell cycle progression significantly.

3.5. Effect of CHM Formula 14 on the Expression Level of Cell Cycle Related Genes. We then examined the expression of cell cycle regulatory proteins to uncover more molecular clues to the effects of Formula 14. Western blot analyses showed that expression of G1/S transition promoting proteins, including cyclin D3, D-type-cyclin-dependent kinase CDK4 and CDK6, and phosphorylated retinoblastoma protein $(\mathrm{pRb})$, the substrate of cyclin D/CDK4/6 complex, was decreased by Formula 14 (Figure 5(a)). The reduced levels of these molecules could result in G1 phase arrest, which is in agreement with the result of the previous cell cycle analysis. In addition to the G1 phase arrest, the G2 phase cell population was also increased in A549 cells after treatment with Formula 14 for $72 \mathrm{hr}$ (Figure 3(a)). We thus further checked the G2/M transition regulating proteins, cyclin B1 and cdc2 (cdk1). Treatment with Formula 14 

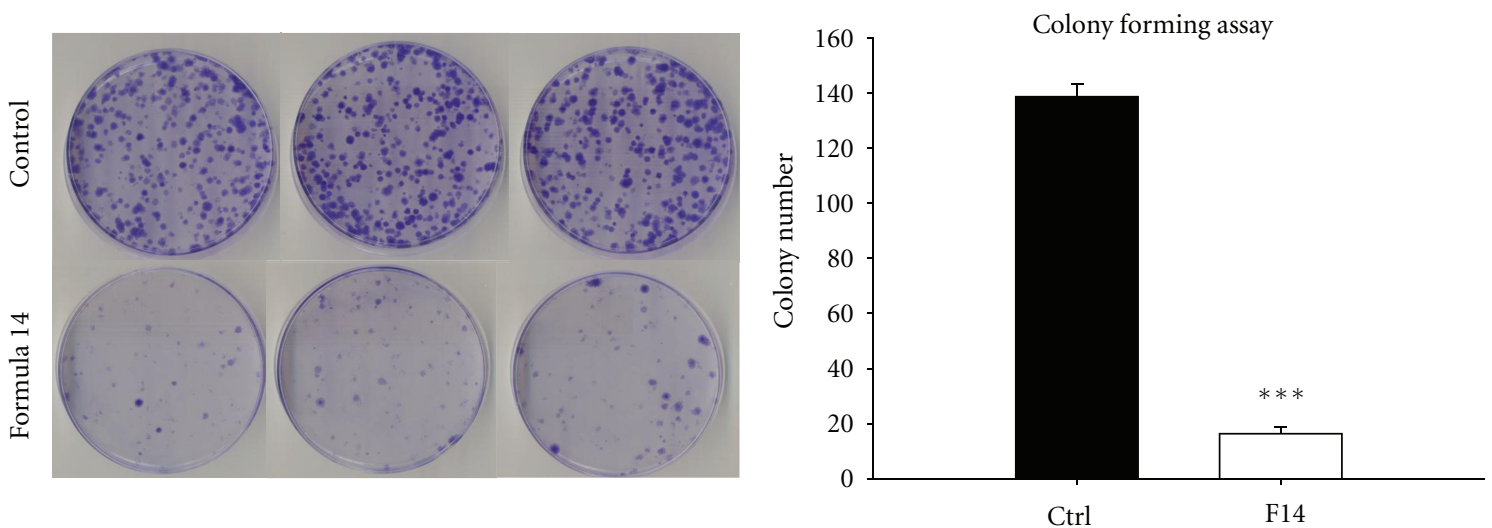

(a)

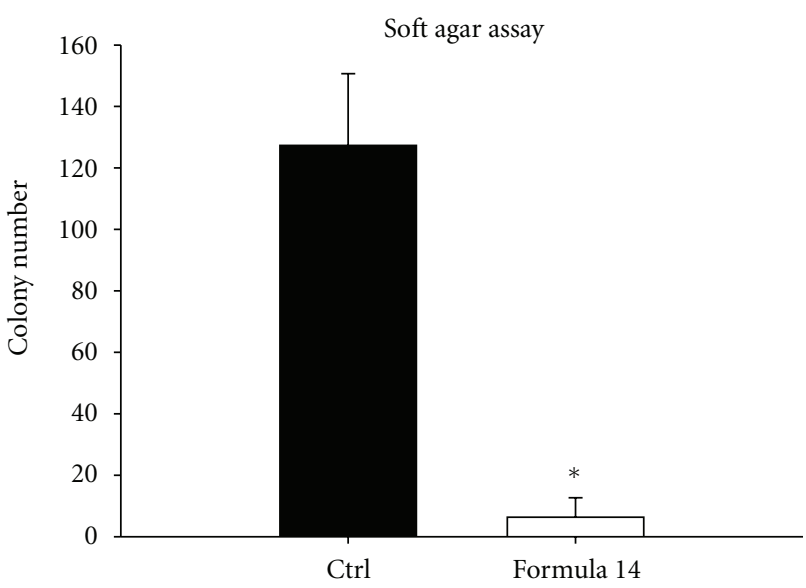

(b)

Figure 3: CHM Formula 14 decreased the colony formation activity of A549 cells. (a) Cell colonies were stained with crystal violet and scanned to generate images. Colony numbers of those cells treated with Formula 14 (lower panel) were significantly decreased. (b) Anchorage-independent growth ability. Colony numbers were significantly decreased by treatment with Formula 14 for 72 hr. Student's $t$-test: ${ }^{*},{ }^{* *} P<0.05$ and 0.001 , respectively.

decreased the expression of both cyclin B1 and phosphorylated cdc2 (Tyr15-p-cdc2) and increased the total amount of all forms of cdc2 (Figure 5(b)). The downregulation of cyclin B1 is in accordance with the G2 arrest effect of Formula 14, while the decreased ratio of Tyr15-pcdc2/total cdc2 may result from the mixed composition of Formula 14.

3.6. Formula 14 Has Similar Effects on Other NSCLC Cell Lines. To examine whether Formula 14 has similar cytotoxicity toward other NSCLC cells, we further applied Formula on H460 (large cell carcinoma) and H520 (squamous cell carcinoma) cell lines. Our results showed that Formula 14 also reduced the proliferation of both $\mathrm{H} 460$ and H520 cells (Figures 6(a) and 6(b)). The $\mathrm{IC}_{50}$ for $\mathrm{H} 460$ and $\mathrm{H} 520$ are $4.5 \%$ and $3.8 \%$, respectively. In addition, Formula 14 also reduced the colony-forming activity of $\mathrm{H} 460$ cell line. The number of colonies at 14-day H460 culture was significantly reduced in cells pretreated with Formula 14 compared to that of the control group (Figure 6(c)). The Western blot analyses showed that Formula 14 decreased the expression levels of cell cycle regulatory proteins, CDK4, pRb, and cyclin B1 of H520 cell line (Figure 6(d)). These data showed that Formula 14 has a general effect on different NSCLC cell lines.

\section{Discussion}

In this study, we used the A549 cell line as an NSCLC model to screen 15 different CHM formulae (Table 1). Some of the 15 formulae are frequently prescribed to cancer patients while the others were considered by TCM physicians to have some potential in treating cancers. Formulae 3, 5 and 14 were identified to substantially reduce the growth of A549 cells but not MRC5 normal lung tissue cells. Formula 14 was used for further investigation in light of its CHM traditional use in lung disease therapy.

Our study reveals that Formula 14 decreased the in vitro tumorigenesis of A549 cells. The A549 lung cancer cell line has been used widely for decades and has stable tumorigenicity. Here, however, cells treated with Formula 


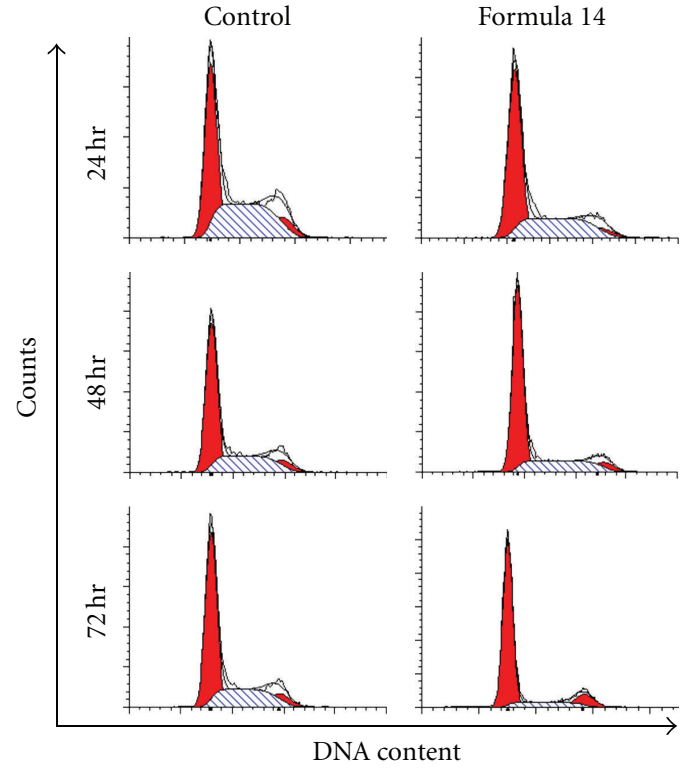

(a)

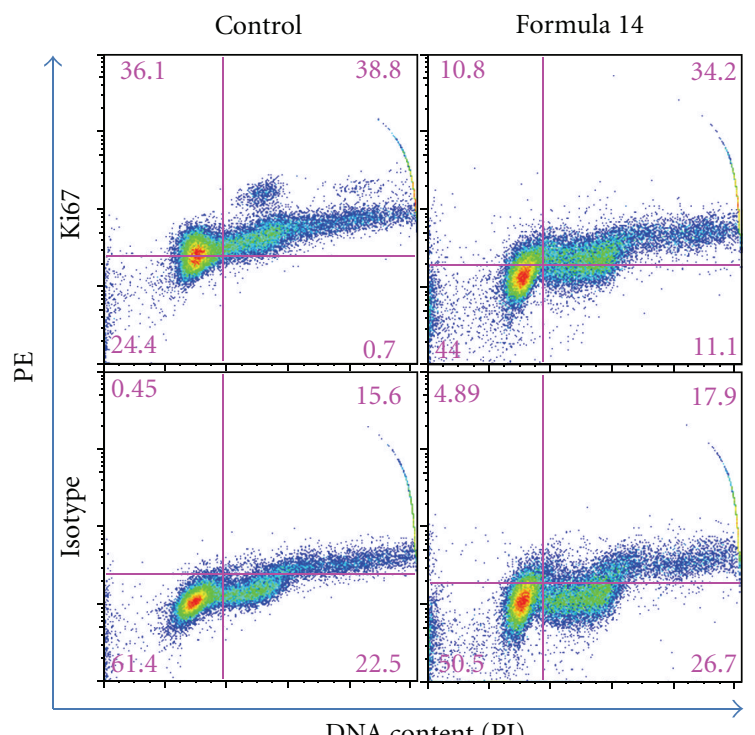

(c)

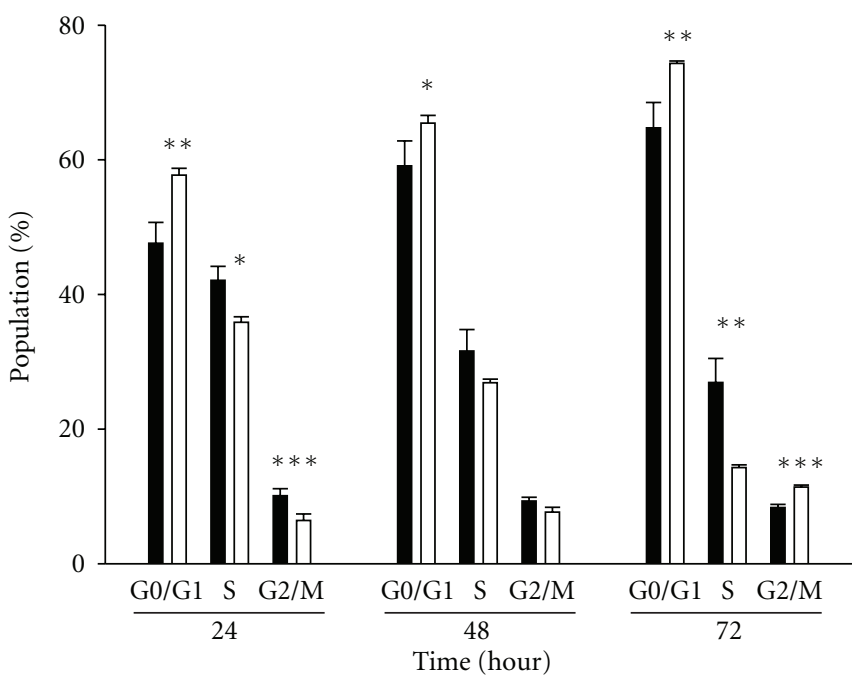

- Control

$\square$ Formula 14

(b)

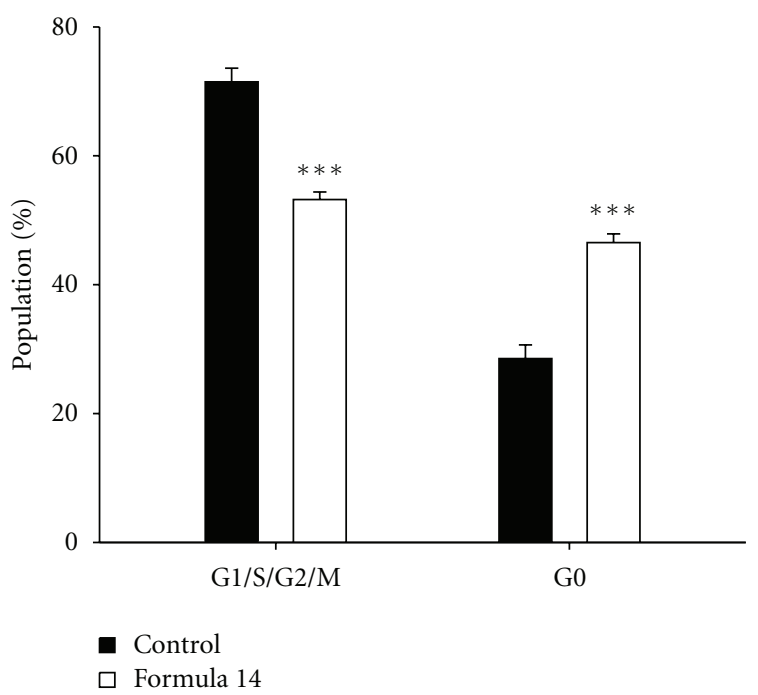

(d)

Figure 4: CHM Formula 14 led to A549 cells arrested in G0/G1 and G2 phase. Cell cycle analysis of A549 cells after treatment with Formula 14. (a) Representative data of cell cycle distribution profile under Formula 14 treatment. Treatment with Formula 14 led to significant cell cycle arrest in G1 and G2 phase. (b) Quantified result of cells at different phases from (a). (c) Representative data of ki67 analysis of A549 cells after a $72 \mathrm{hr}$ treatment of Formula 14. (d) Fraction of cells in G0 and other phases. Formula 14 significantly increased the G0 cell population after $72 \mathrm{hr}$ treatment. Student's $t$-test: ${ }^{*},{ }^{* *},{ }^{* *} P<0.05,0.01$, and 0.001 , respectively.

14 showed significantly reduced colony formation in both media and soft agar over long culture periods (14-30 days) compared to the control cells. Human lung tumor xenografts in immunosuppressed mice will be conducted in future to explore the in vivo antitumorigenic effects of Formula 14 treatment.

The growth of A549 cells was significantly reduced by Formula 14 treatment, which could be a result of either inhibiting proliferation or increasing cell death. We suggest that the cell growth reduction by Formula 14-treatment must be attributed to a specific inhibition of cell proliferation rather than induction of apoptosis. The annexin $\mathrm{V}$ and PI double staining experiments showed that Formula 14 treatment did not influence the A549 cell distribution in normal (both annexin V and PI negative), early apoptotic (annexin $\mathrm{V}$ positive and PI negative), and late apoptotic or necrotic (both annexin $\mathrm{V}$ and PI positive) populations. Fewer than $2 \%$ of cells were distributed in the early or late apoptosis populations. In addition, the A549 cell cycle profile obtained from the PI staining revealed there was no subG1 

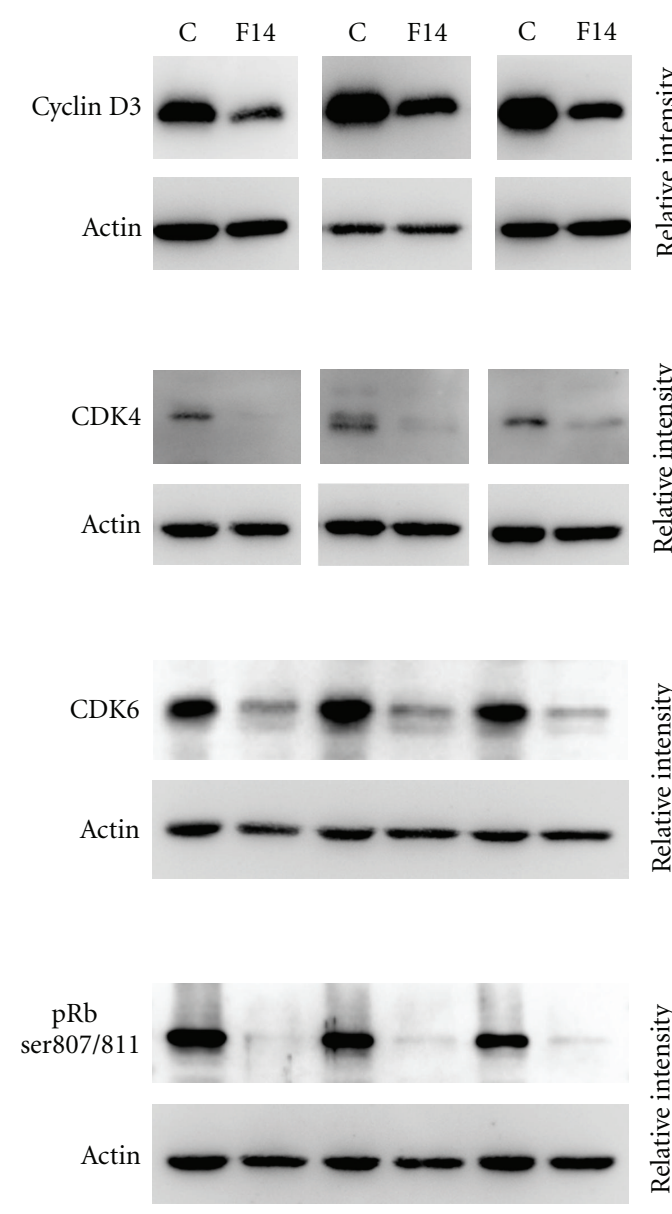

(a)
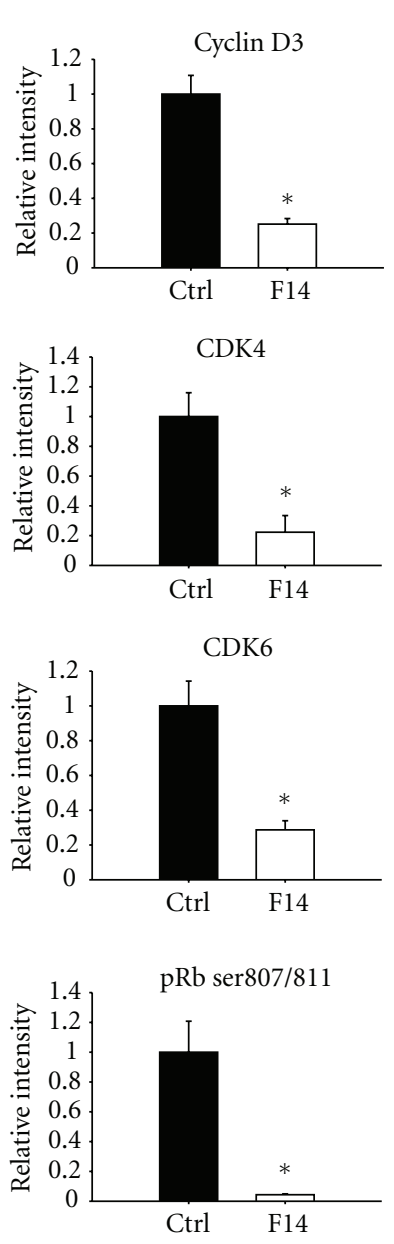
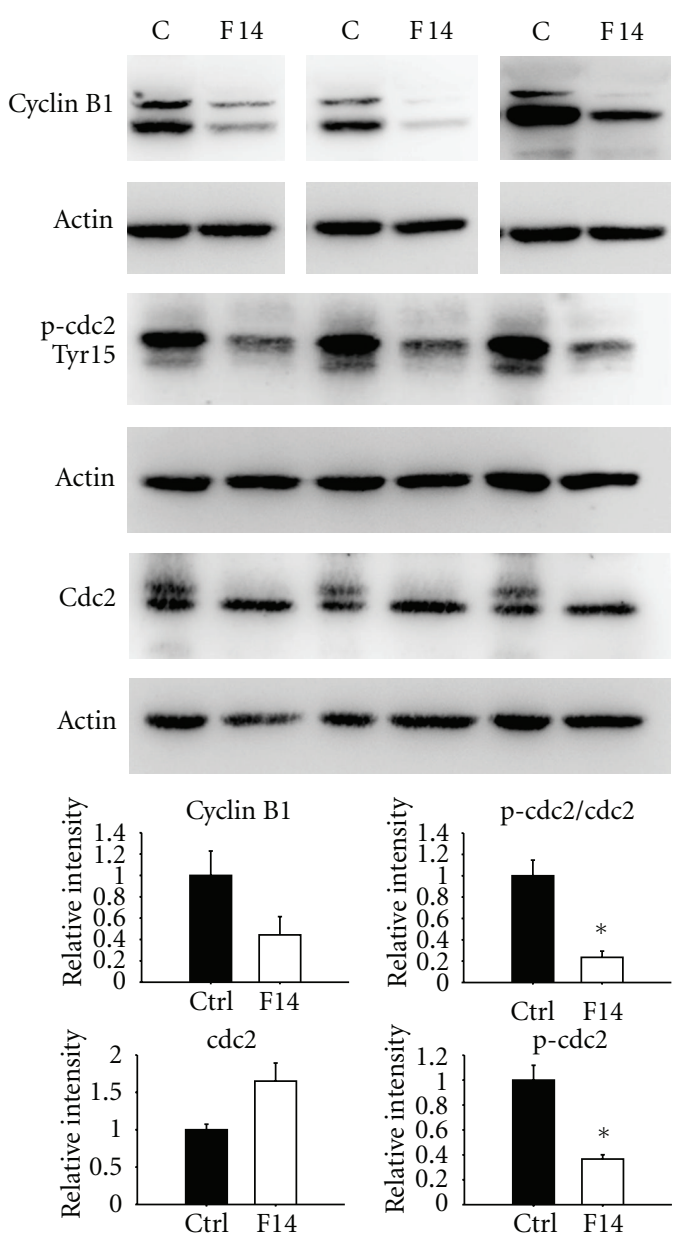

(b)

Figure 5: Western blots of the G1/S and G2/M regulatory proteins in A549 cells after $72 \mathrm{hr}$ treatment of Formula 14. (a) Examination of A549 G1/S regulatory protein levels after treatment with Formula 14 for $72 \mathrm{hr}$. The expression levels of cyclin D3, CDK4, and CDK6 and the phosphorylation of $\mathrm{Rb}$ were significantly decreased after treatment with Formula 14. (b) Western blots of cyclin B1, phosphorylated cdc2, and total cdc2. The expression levels of cyclin B1 and the phosphorylation of cdc2 were decreased, while the expression of cdc2 was increased after treatment with Formula 14. Results of 3 independent experiments were shown at the same time to show the consistent results. Student's $t$-test: ${ }^{*} P<0.05 .(n=3)$.

(apoptotic) cell population. All of these observations suggest that Formula 14 did not induce apoptosis in A549 cells. Indeed, the cell cycle analyses showed that both G1 and G2 phase arrest were induced in A549 cells by Formula 14. These data together explain why Formula 14 suppressed the cell growth without causing the cell death. We also noticed significant G1 arrest in cells treated with Formula 14 for only 24 hr, while G2 arrest was not evident until 72 hr had elapsed.

We also examined the expression levels of regulators involved in the cell cycle. Substantial decline of the G1/S regulatory proteins (cyclin D3, CDK4, and CDK6) was identified by Western blot analysis, which is in accordance with the G1 arrest results obtained from cell cycle analysis. We found that the phosphorylation of Rb (Ser807/811) was also downregulated after treatment. $\mathrm{Rb}$ is a tumor suppressor protein that regulates cell proliferation by controlling progression through the G1 restriction point of the cell cycle. Phosphorylation by cyclin D-CDK4/6 and cyclin E-CDK2 causes $\mathrm{Rb}$ inactivation, thus allowing cell cycle progression [21-23]. Our result indicates that levels of these critical regulators involved in G1/S promotion were severely reduced by Formula 14.

However, Formula 14 seemed to have a more complicated effect toward G2/M cell cycle regulation. Formula 14 treatment decreased not only the expression of cyclin B1 but also the Tyr-15 phosphorylated (pY15) form of cdc2. Cell cycle G2/M progression is regulated by the cdc2-cyclin B1 kinase complex and is maintained in an inactive form by phosphorylation at Thr14/Tyr15 of cdc2 [24]. Entry into the $\mathrm{M}$-phase of the cell cycle is regulated by activation of cdc2 kinase through cyclin B1 binding and dephosphorylation of cdc2 at Thr14/Tyr15 [25, 26]. Although the level of Tyr15-p-cdc2 was reduced by Formula 14, which would tend to promote the $\mathrm{G} 2 / \mathrm{M}$ progression, the severe reduction of cyclin B1 would tend to decrease the formation of cyclin B1-cdc2 complex. We suggest that the accumulation 


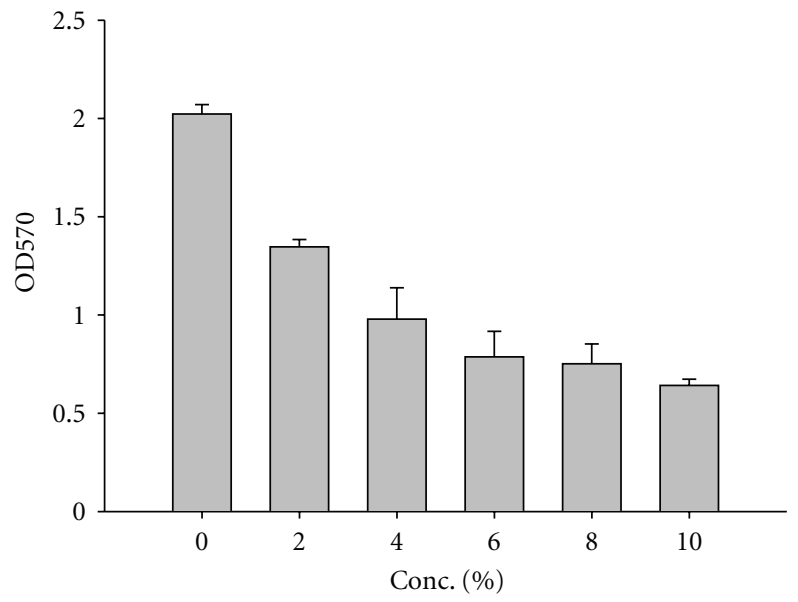

(a)

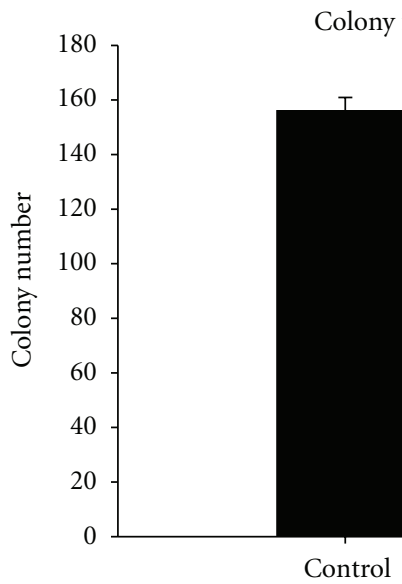

forming assay
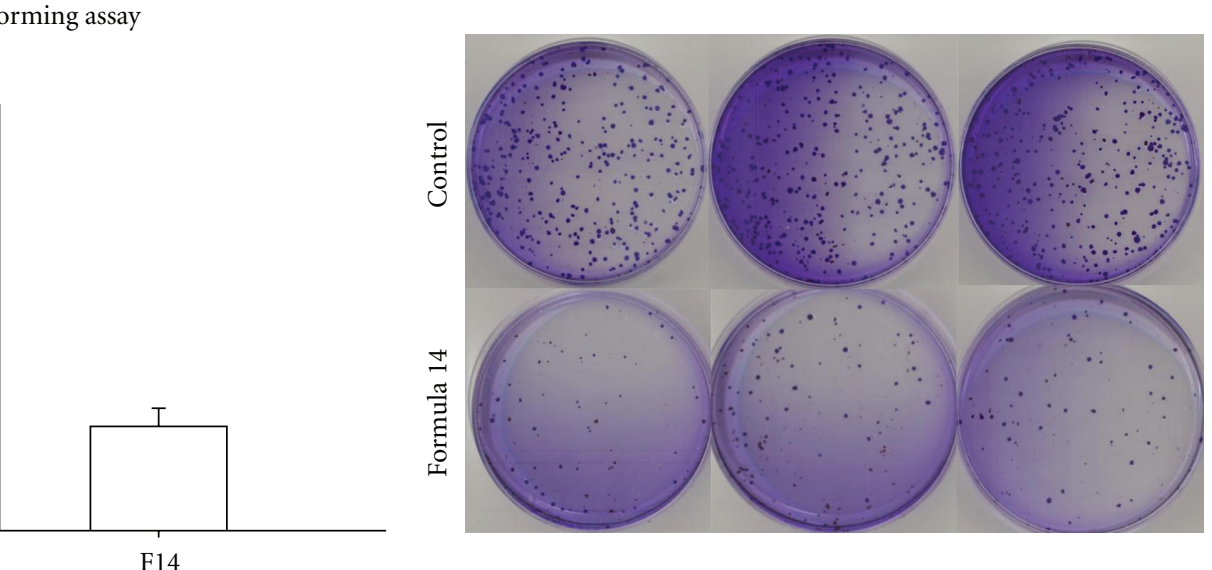

(c)

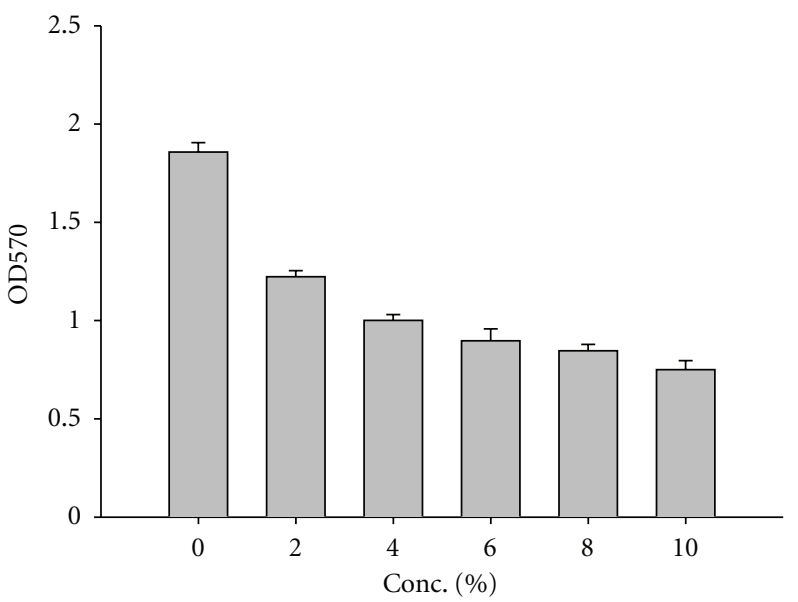

(b)

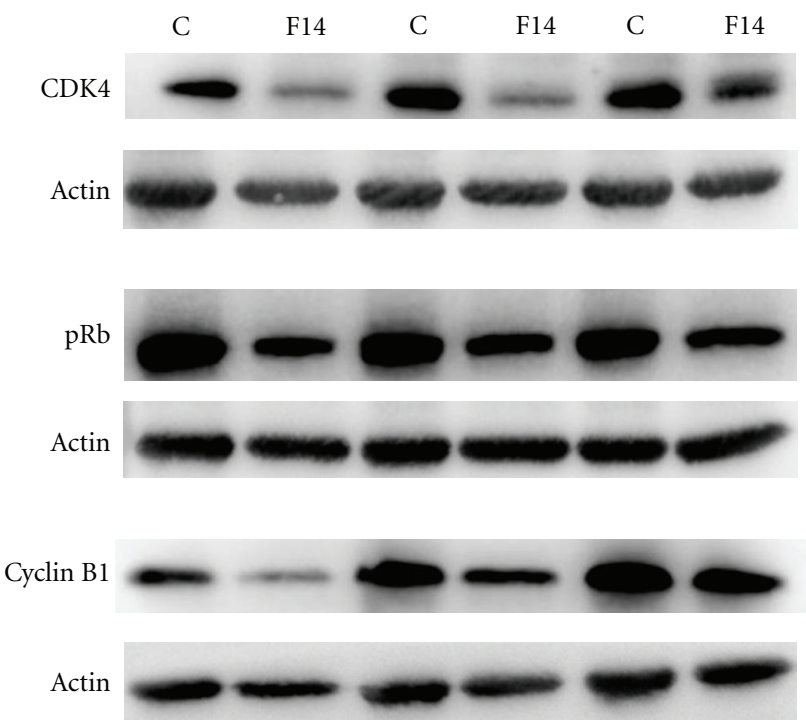

(d)

FIGURE 6: The effect of Formula 14 on NSCLC cell lines H460 and H520. Survival rate of H460 (a) and H520 (b) cells following treatment with Formulae14 for $72 \mathrm{hr}$ was analyzed by MTT assay. (c) Formula 14 decreased the colony formation activity of H460 cells. Cell colonies were stained with crystal violet and scanned to generate images. Colony numbers of those cells treated with Formula 14 (lower panel) were significantly decreased. (d) Western blots of the cell cycle regulatory proteins in H520 cells after $72 \mathrm{hr}$ treatment of Formula 14. Results of 3 independent experiments were shown at the same time to show the consistent results. 
of cells in G2/M after Formula 14 treatment for $72 \mathrm{hr}$ might be caused by the profound reduction of cyclin B1. We suspect that different ingredients in Formula 14 have different targets toward the cell cycle, which will need further investigation.

To further investigate whether Formula 14 has a general effect toward NSCLC cell lines, we examine the viability of another two NSCLC cell lines, H460 and H520, after treatment with Formula 14. The study showed that $\mathrm{IC}_{50}$ of these two cell lines were smaller than that of A549 cells, which suggest Formula 14 could inhibit the growth of H460 and H520 effectively. Results of colony-forming and Western blot analyses further provide the evidence that Formula 14 could suppress the tumorigenicity and cell cycle progression activities of H460 and H520 cells. Based on these observations, we conclude that Formula 14 has similar effect on NSCLC cell lines.

Formula 14 is the standard formulation of Gui-ZhiTang with the addition of Scutellariae baicalensis to create another formula known as Yang-Dan-Tang. It was recently reported that the crude ethanolic extracts of Scutellariae baicalensis were selectively toxic to human lung cancer cell lines [27]. Several investigations on constituent herbs of Formula 14 have revealed several pure compounds possessing various biological activities. Isoliquiritigenin isolated from Glycyrrhizae uralensis has been shown to induce apoptosis in colorectal cancer cell lines [28]. Baicalein, baicalin, oroxylin A, and wogonin are effective compounds from Scutellariae baicalensis and were identified to have antiproliferation and proapoptosis ability [29-32]. Crude extracts of Fructus Zizyphi Jujubae and Rhizoma Zingiberis were shown to block angiogenesis [33] and enhance paclitaxel sensitivity [34], respectively. Water extract of Paeoniae Rubrae was also reported to have apoptotic effect on hepatocellular carcinoma cells [35]. In our study, we found Formula 14 could induce cell cycle arrest, as several previous reports also show; however, we did not observe obvious apoptosis of A549 cells after treatment with the formula. One possible explanation is there might be interaction between different herb constituents of this formula which could lead to complicated effects. Another factor that might affect the herb effects is serum concentration in the growth media. Most studies observed apoptotic events when using a low serum $(0 \sim 5 \%)$ condition [36-38], whereas we used a higher serum $(10 \%)$ condition in this study, which could provide stronger survival signals or, alternatively, generate a stronger serum binding effect to compromise the herb effects. On the other hand, Formula 14 could not induce apoptosis but arrest cells at G1/G2 phases of cell cycle, suggesting a cytostatic activity for lung tumor. The significance of cytostasis in anticancer drug activity drew more attention as drug development efforts have moved from conventional chemotherapy to target therapy. However, it is suggested that a prolonged arrest in a cell cycle stage other than G0 is intolerable to a cell and must be resolved by either initiating a cell death or escaping from the cell-cycle block [39]. Therefore, it is important to examine the issue whether a continuous long-term administration of Formulas 14 could have tumor-shrinkage effect in the further investigation with xenograft mouse model.

\section{Conclusion}

We identified 3 potential formulae that could substantially decrease the survival of NSCLC cells while not affecting MRC5 normal lung cells. Formula 14, the Yang-DanTang, was chosen for further study for its effect on cell growth suppression. A colony-forming assay demonstrated that Formula 14 has antitumorigenic activity. In addition, flow cytometry showed that Formula 14 induced cell cycle arrest in G1 and G2 phase without causing significant cell death. This result was further confirmed by western blot analysis which showed reduced expression of G1/S and G2/M regulators. Our study provides further insight into the working mechanism of Chinese medicine formulae in patients.

\section{Acknowledgments}

The authors thank Dr. Harry Wilson (OIST, Japan) for critical reading of this paper, and Yuan-Ta Lin and ChenMing Hsu for their technical assistance. Their gratitude is also extended to the Academic Paper Editing Clinic and the Confocal Microscope Core Facility, NTNU. This work was supported by Research Grants (96TOP001 and NTNU100D-02) from the National Taiwan Normal University.

\section{References}

[1] W. D. Travis, L. B. Travis, and S. S. Devesa, "Lung cancer," Cancer, vol. 75, no. 1, pp. 191-202, 1995.

[2] C. A. Liu and M. Peng, "Dictionary of Chinese anti-cancer herbal medicine," Hubei: Hubei Science and Technology Press, Tumor Index, 1994.

[3] P. W. Li, Comprehensive Diagnosis and Treatment for LC, China Chinese Medicine Press, Beijing, China, 2001.

[4] X. Z. Guo and C. L. Song, "The regulation of herbal application for lung cancer," Liaoning Journal of Traditional Chinese Medicine, vol. 29, no. 5, p. 273, 2002.

[5] S. Y. Pan, S. B. Chen, H. G. Dong et al., "New perspectives on chinese herbal medicine (Zhong-Yao) research and development," Evidence-Based Complementary and Alternative Medicine, vol. 2011, Article ID 403709, 11 pages, 2011.

[6] T. Kamei, H. Kumano, K. Iwata, Y. Nariai, and T. Matsumoto, "The effect of a traditional Chinese prescription for a case of lung carcinoma," Journal of Alternative and Complementary Medicine, vol. 6, no. 6, pp. 557-559, 2000.

[7] C. L. Saw, Q. Wu, and A. N. T. Kong, "Anti-cancer and potential chemopreventive actions of ginseng by activating Nrf2 (NFE2L2) anti-oxidative stress/anti-inflammatory pathways," Chinese Medicine, vol. 5, article 37, 2010.

[8] R. V. Ancuceanu and V. Istudor, "Pharmacologically active natural compounds for lung cancer," Alternative Medicine Review, vol. 9, no. 4, pp. 402-419, 2004.

[9] Y. L. Hsu, C. Y. Cho, P. L. Kuo, Y. T. Huang, and C. C. Lin, "Plumbagin (5-hydroxy-2-methyl-1,4-naphthoquinone) induces apoptosis and cell cycle arrest in A549 cells through p53 accumulation via c-Jun $\mathrm{NH}_{2}$-terminal kinase-mediated phosphorylation at serine 15 in vitro and in vivo," Journal of 
Pharmacology and Experimental Therapeutics, vol. 318, no. 2, pp. 484-494, 2006.

[10] J. W. Lee, H. Y. Min, A. R. Han et al., "Growth inhibition and induction of G1 phase cell cycle arrest in human lung cancer cells by a phenylbutenoid dimer isolated from Zingiber cassumunar," Biological and Pharmaceutical Bulletin, vol. 30, no. 8, pp. 1561-1564, 2007.

[11] J. Parada-Turska, R. Paduch, M. Majdan, M. KandeferSzerszeń, and W. Rzeski, "Antiproliferative activity of parthenolide against three human cancer cell lines and human umbilical vein endothelial cells," Pharmacological Reports, vol. 59, no. 2, pp. 233-237, 2007.

[12] W. D. Zhang, H. R. Zhao, Y. Yan, X. H. Wang, Z. H. Zong, and Y. Liu, "Apoptosis induced by cantharidin in human pulmonary carcinoma cells A549 and its molecular mechanisms," Zhonghua zhong liu za zhi, vol. 27, no. 6, pp. 330-334, 2005.

[13] Q. Chen, Y. Wang, K. Xu et al., "Curcumin induces apoptosis in human lung adenocarcinoma A549 cells through a reactive oxygen species-dependent mitochondrial signaling pathway," Oncology Reports, vol. 23, no. 2, pp. 397-403, 2010.

[14] Q. Li, H. Cheng, G. Zhu et al., "Gambogenic acid inhibits proliferation of A549 cells through apoptosis-inducing and cell cycle arresting," Biological and Pharmaceutical Bulletin, vol. 33, no. 3, pp. 415-420, 2010.

[15] S. Y. Park, H. S. Kim, E. K. Cho et al., "Curcumin protected PC12 cells against beta-amyloid-induced toxicity through the inhibition of oxidative damage and tau hyperphosphorylation," Food and Chemical Toxicology, vol. 46, no. 8, pp. 28812887, 2008.

[16] H. Wu, C. L. Pan, Y. C. Yao, S. S. Chang, S. L. Li, and T. F. $\mathrm{Wu}$, "Proteomic analysis of the effect of Antrodia camphorata extract on human lung cancer A549 cell," Proteomics, vol. 6, no. 3, pp. 826-835, 2006.

[17] Y. L. Cheng, W. L. Chang, S. C. Lee et al., "Acetone extract of Bupleurum scorzonerifolium inhibits proliferation of A549 human lung cancer cells via inducing apoptosis and suppressing telomerase activity," Life Sciences, vol. 73, no. 18, pp. 2383-2394, 2003.

[18] J. Y. Hong, J. W. Nam, E. K. Seo, and S. K. Lee, "Daphnane diterpene esters with anti-proliferative activities against human lung cancer cells from Daphne genkwa," Chemical and Pharmaceutical Bulletin, vol. 58, no. 2, pp. 234-237, 2010.

[19] M. Zhang, X. Zhang, C. X. Bai, J. Chen, and M. Q. Wei, "Inhibition of epidermal growth factor receptor expression by RNA interference in A549 cells," Acta Pharmacologica Sinica, vol. 25, no. 1, pp. 61-67, 2004.

[20] K. Miyashita, "Insulin stimulates colony formation at a nonpermissive temperature by thermosensitive mutants of Chinese hamster lung cells that exhibit anchorage-independent growth in soft-agar culture," Cell Structure and Function, vol. 18, no. 5, pp. 303-314, 1993.

[21] M. Hatakeyama and R. A. Weinberg, "The role of RB in cell cycle control," Progress in Cell Cycle Research, vol. 1, pp. 9-19, 1995.

[22] S. A. Ezhevsky, A. Ho, M. Becker-Hapak, P. K. Davis, and S. F. Dowdy, "Differential regulation of retinoblastoma tumor suppressor protein by G1 cyclin-dependent kinase complexes in vivo," Molecular and Cellular Biology, vol. 21, no. 14, pp. 4773-4784, 2001.

[23] S. A. Ezhevsky, H. Nagahara, A. M. Vocero-Akbani, D. R. Gius, M. C. Wei, and S. F. Dowdy, "Hypo-phosphorylation of the retinoblastoma protein ( $\mathrm{pRb}$ ) by cyclin $\mathrm{D}$ : Cdk4/6 complexes results in active pRb," Proceedings of the National Academy of
Sciences of the United States of America, vol. 94, no. 20, pp. 10699-10704, 1997.

[24] B. Hu, J. Mitra, S. van den Heuvel, and G. H. Enders, "S and $\mathrm{G}_{2}$ phase roles for Cdk2 revealed by inducible expression of a dominant-negative mutant in human cells," Molecular and Cellular Biology, vol. 21, no. 8, pp. 2755-2766, 2001.

[25] T. Izumi and J. L. Mailer, "Phosphorylation and activation of the Xenopus Cdc25 phosphatase in the absence of Cdc2 and Cdk2 kinase activity," Molecular Biology of the Cell, vol. 6, no. 2, pp. 215-226, 1995.

[26] V. A. J. Smits and R. H. Medema, "Checking out the $\mathrm{G}_{2} / \mathrm{M}$ transition," Biochimica et Biophysica Acta, vol. 1519, no. 1-2, pp. 1-12, 2001.

[27] J. Gao, W. A. Morgan, A. Sanchez-Medina, and O. Corcoran, "The ethanol extract of Scutellaria baicalensis and the active compounds induce cell cycle arrest and apoptosis including upregulation of p53 and Bax in human lung cancer cells," Toxicology and Applied Pharmacology, vol. 254, no. 3, pp. 221228, 2011.

[28] T. Takahashi, N. Takasuka, M. Iigo et al., "Isoliquiritigenin, a flavonoid from licorice, reduces prostaglandin $\mathrm{E}_{2}$ and nitric oxide, causes apoptosis, and suppresses aberrant crypt foci development," Cancer Science, vol. 95, no. 5, pp. 448-453, 2004.

[29] R. Mu, Q. Qi, H. Gu et al., "Involvement of p53 in oroxylin Ainduced apoptosis in cancer cells," Molecular Carcinogenesis, vol. 48, no. 12, pp. 1159-1169, 2009.

[30] Y. C. Chang, T. H. Tseng, M. J. Lee, J. D. Hsu, and C. J. Wang, "Induction of apoptosis by penta-acetyl geniposide in rat C6 glioma cells," Chemico-Biological Interactions, vol. 141, no. 3, pp. 243-257, 2002.

[31] W. R. Lee, S. C. Shen, H. Y. Lin, W. C. Hou, L. L. Yang, and Y. C. Chen, "Wogonin and fisetin induce apoptosis in human promyeloleukemic cells, accompanied by a decrease of reactive oxygen species, and activation of caspase 3 and $\mathrm{Ca}^{2+}$ dependent endonuclease," Biochemical Pharmacology, vol. 63, no. 2, pp. 225-236, 2002.

[32] Z. Ma, K. I. Otsuyama, S. Liu et al., "Baicalein, a component of Scutellaria radix from Huang-Lian-Jie-Du-Tang (HLJDT), leads to suppression of proliferation and induction of apoptosis in human myeloma cells," Blood, vol. 105, no. 8, pp. 33123318, 2005.

[33] S. W. Kang, J. S. Choi, J. Y. Bae et al., "Blockade of vascular angiogenesis by Aspergillus usamii var. shirousamiitransformed Angelicae Gigantis Radix and Zizyphus jujuba," Nutrition Research and Practice, vol. 3, no. 1, pp. 3-8, 2009.

[34] K. Takara, S. Horibe, Y. Obata, E. Yoshikawa, N. Ohnishi, and T. Yokoyama, "Effects of 19 herbal extracts on the sensitivity to paclitaxel or 5-fluorouracil in HeLa cells," Biological and Pharmaceutical Bulletin, vol. 28, no. 1, pp. 138-142, 2005.

[35] S. Hu, S. M. Chen, X. K. Li, R. Qin, and Z. N. Mei, "Antitumor effects of Chi-Shen extract from Salvia miltiorrhiza and Paeoniae radix on human hepatocellular carcinoma cells," Acta Pharmacologica Sinica, vol. 28, no. 8, pp. 1215-1223, 2007.

[36] D. W. Choi, "Calcium-mediated neurotoxicity: relationship to specific channel types and role in ischemic damage," Trends in Neurosciences, vol. 11, no. 10, pp. 465-469, 1988.

[37] E. H. Jo, S. H. Kim, J. C. Ra et al., "Chemopreventive properties of the ethanol extract of chinese licorice (Glycyrrhiza uralensis) root: induction of apoptosis and G1 cell cycle arrest in MCF-7 
human breast cancer cells," Cancer Letters, vol. 230, no. 2, pp. 239-247, 2005.

[38] M. R. Seon, S. S. Lim, H. J. Choi et al., "Isoangustone a present in hexane/ethanol extract of Glycyrrhiza uralensis induces apoptosis in DU145 human prostate cancer cells via the activation of DR4 and intrinsic apoptosis pathway," Molecular Nutrition and Food Research, vol. 54, no. 9, pp. 1329-1339, 2010.

[39] O. Rixe and T. Fojo, "Is cell death a critical end point for anticancer therapies or is cytostasis sufficient?" Clinical Cancer Research, vol. 13, no. 24, pp. 7280-7287, 2007. 


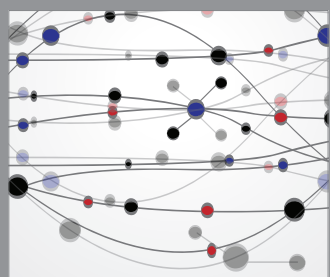

The Scientific World Journal
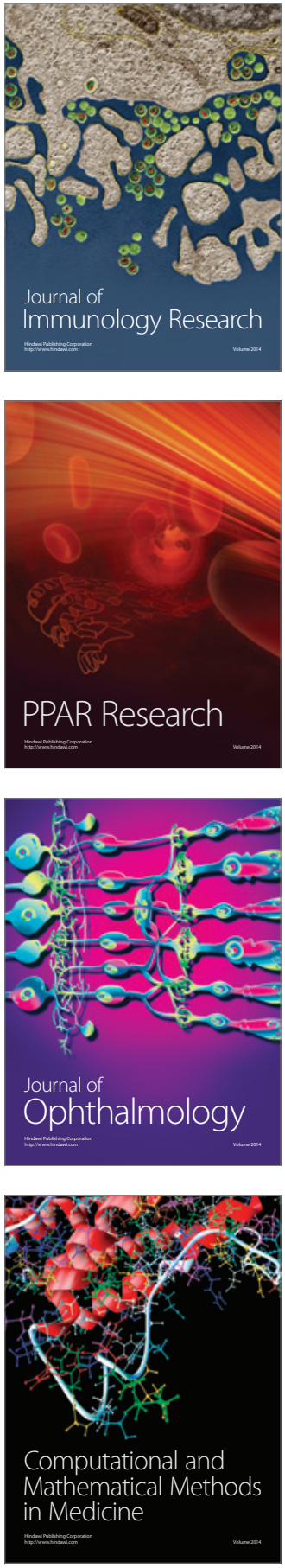

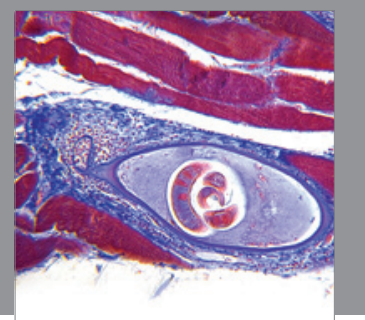

Gastroenterology

Research and Practice
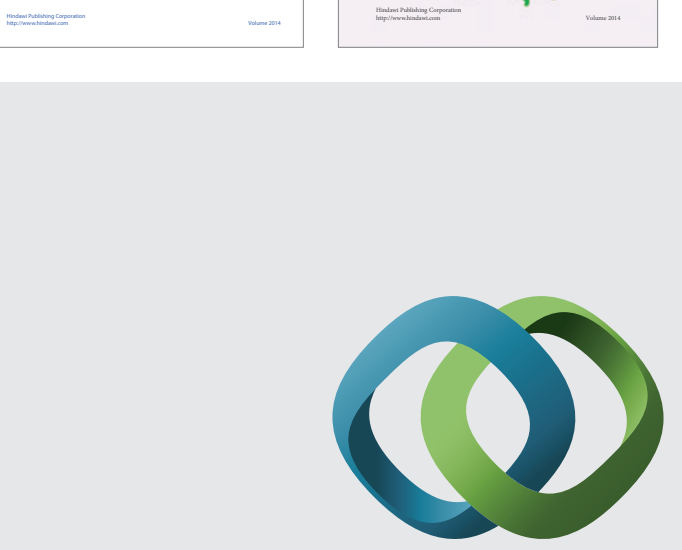

\section{Hindawi}

Submit your manuscripts at

http://www.hindawi.com
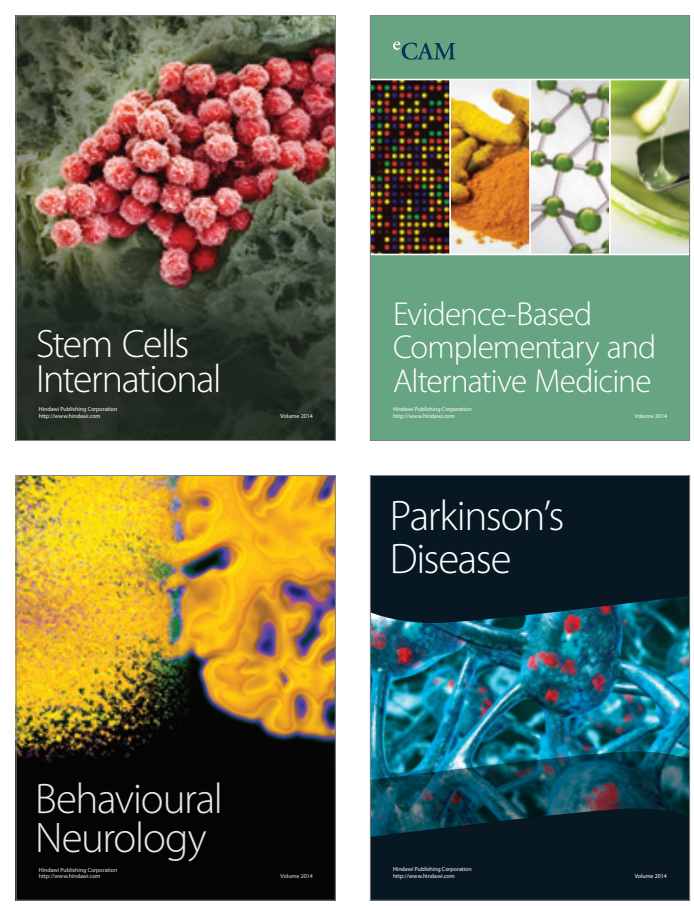

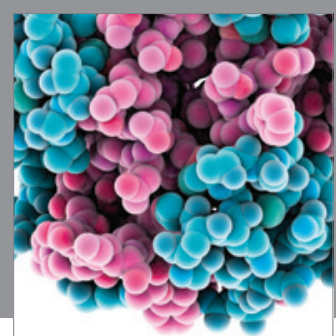

Journal of
Diabetes Research

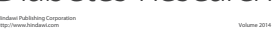

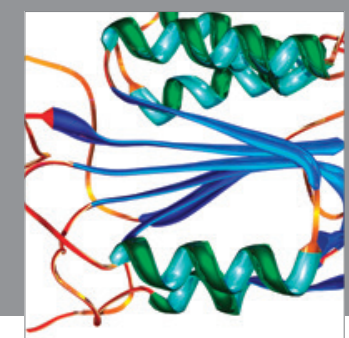

Disease Markers
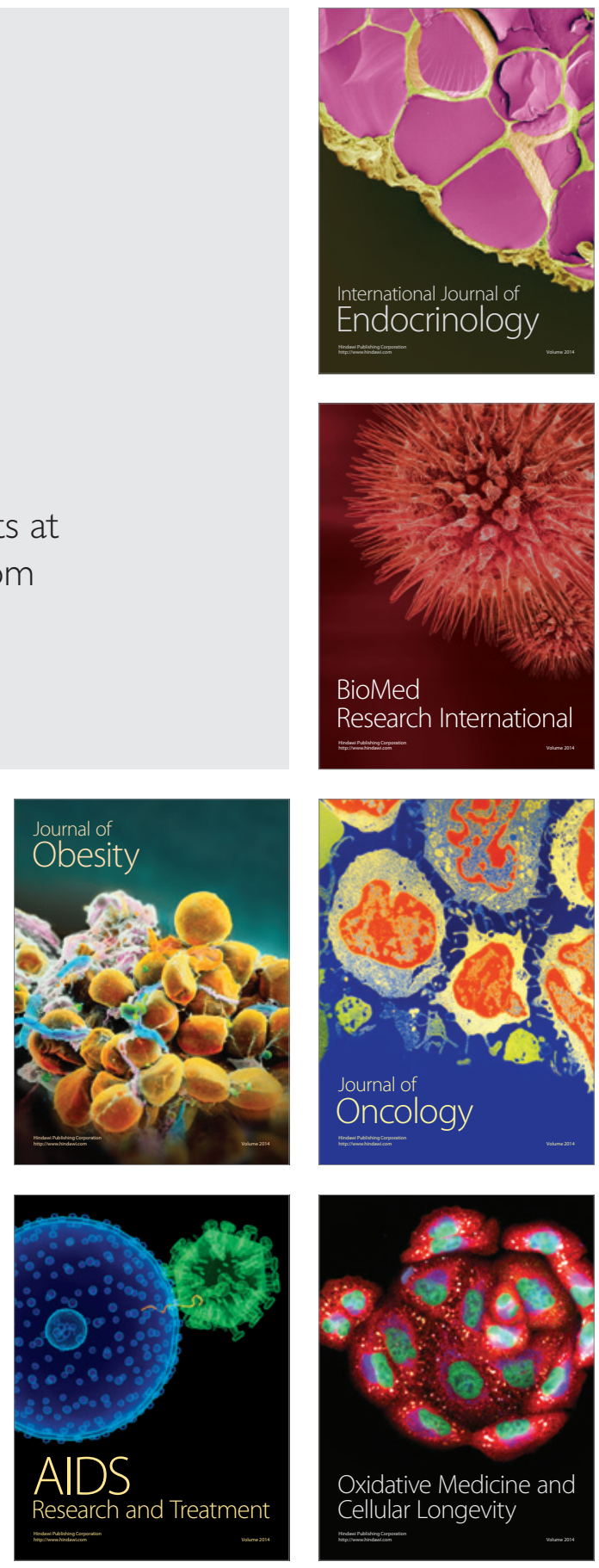